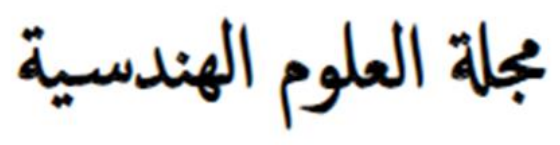

\title{
Development of a computational Procedure for Optimum Sediment Removal: Application to case of Roseires Hydropower Intakes
}

\author{
Siyam A. $\mathbf{M}^{1 *}$, Kantoush S. $\mathrm{A}^{2}$ and Saad A. $\mathrm{S}^{3}$ \\ 1 Associate Professor, UNESCO Chair in Water Resources, Faculty of Engineering Sciences, Omdurman Islamic University, Sudan, \\ ASMASCE \\ 2 Associate Professor, Disaster Prevention Research Institute (DPRI), Kyoto University \\ 3 Sudanese Hydropower Generation Company, Ministry of Water Resources and Electricity, Sudan \\ * Corresponding author: Siyam A. M. e-mail (amsiyam@oiu.edu.sd).
}

Article history: Received 30 October 2019, Received in revised form 14 January 2021, Accepted 14 January 2021

\begin{abstract}
Hydropower generation is one of the key purposes that dams were built for. World-wide the sustainability of hydropower operation is deprived and threatened by the alarming rate of reservoir sedimentation. The situation is even worst for the cases where the sediment delta has propagated and reached the dam site. Various sediment management practices have been employed to cope with the problem at a huge amount of cost. This paper analyses the sedimentation problem and the impact on hydropower generation in Roseires reservoir, in Sudan. An economical reservoir sediment management plan such as Hydro-suction dredging technique is suggested. The deposited sediment should be agitated before being bypassed to the downstream via a pipeline that makes use of the natural hydraulic head of water. A detailed design procedure is outlined and guidelines for the optimization are presented. The procedure is theoretically illustrated by applying it to remove the annual deposited sediment ahead of Roseires Hydropower intakes in Sudan. It was concluded that such system is cost effective when compared to costs incurred in tackling the effect of siltation in front of hydropower intakes.
\end{abstract}

Keywords: Hydropower intakes, sediment transport in pipes, hydro-suction dredging, optimum velocity, sediment removal, Roseires Reservoir.

\section{INTRODUCTION}

World-wide reservoirs are losing their capacity at various rates due to the inevitable natural processes of sedimentation [1]. This is threatening the functional purposes of reservoirs in many aspects. The loss in storage affects hydropower generation, irrigation, water supply, flood levels and control, and gradually affects the sustainability of the project as a whole. In many cases the deposited sediment delta fronts have reached to the dam sites and hamper the continuous production of energy from the hydropower generation units. Various mitigation measures are currently employed to mitigate the problem. These measures span from sediment sluicing, flushing, and dredging and more recently check dams and sediment bypassing [2], [3], [4]. So far dredging method is only applied conventionally to remove limited deposited volumes at very high cost [4]. A modified dredging technique, called Hydro-Suction Dredging (HSD), has been recently proposed and advocated for dealing with localized deposited sediments such as in front of intakes [5], [6], [7].

The HSD system involves mechanical agitation of the deposited sediment and then transports the sediment via a pipeline to a suitable dumping 
site. The dumping site might be on shoreline, deep section of the main river channel or downstream of the dam. If properly designed, this system has the advantage of considerable saving in cost as a result of eliminating the use of pumps for transport, ease of maneuverability and low maintenance cost. Siphon dredging system implemented at Wonogiridan in Indonesia was reported by [7]. The system was efficiently utilized to remove sediment and transported to a disposal unit through the sediment discharge pipe of diameter $400 \mathrm{~mm}$.

Thus the proposed management system comprises three integrated units, the suction, conveying and disposal. The hydro suction dredging system for cutting the deposited sediment from reservoir bed and deliver a pipeline system to transport the sediment to a suitable discharge site on the downstream. The pipeline will rely on the natural hydraulic head available to deliver optimally defined and known sediment load that will be automatically fed into by the HSD system. Fig. (1) Presents schematically the layout of the HSD-pipeline system. The main pipeline may include temporal or permanent lateral pipes that are well distributed to enable evacuation of deposited sediment from the designated area. Hopefully, if the size of the pipe required is small and the length is not so long, a flexible pipe can be used and its maneuverability may be achieved. Hence, a complicated pipe network may be not necessary.

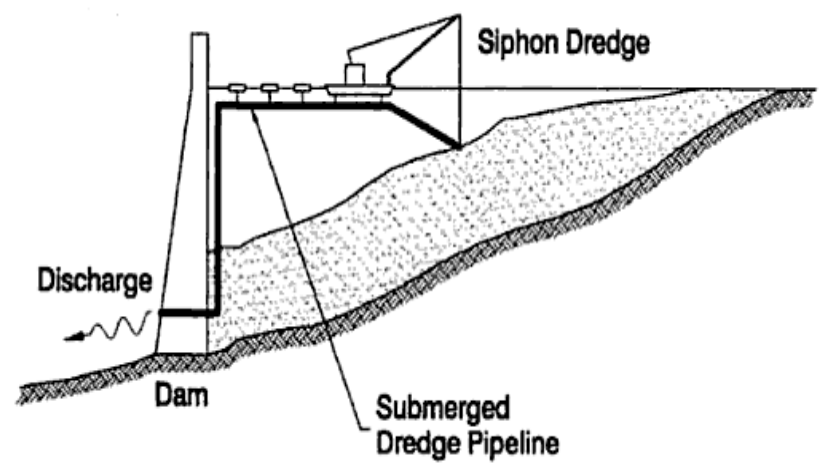

Fig. (1): Schematic layout the proposed HSD-Pipeline system

The objective of this paper is to investigate use of the HSD as an option for sediment removal a head of hydropower intakes of Roseires reservoir in Sudan instead of the costly conventional dredging method. Also the paper aims to detail the calculation procedure for selecting the suitable size of the pipe line that transport the sediment optimally considering the case of deposited sediment in Roseires reservoir as a practical example.

\section{MATERIAL AND METHODS}

This research study has been carried out via accomplishment of many activities that comprise

- Collection of data pertaining to Roseires Hydropower intake;

- Literature Survey of previous methods of estimating sediment transport in pipes;

- Development of a design guideline for computing optimum sediment removal;

- Applying the computational procedure to the case of Roseires Hydropower intake

\section{A. Data pertaining to Roseires Hydropower Intakes.}

Apart from the impact of sedimentation on loss of storage, sediment, especially sand particles, ingress into turbine units creates a lot of problems. It causes rapid wear out of the turbine components especially the blades, blockage of the cooling system, and overall loss in performance of the turbine units [8]. In addition occasional blockage of the intakes is an inevitable as in case of Roseires reservoir in Sudan. Usually when the pressure drops in penstock of a turbine unit, the unit load will decrease and the alarm system will indicate that the intake needs cleaning. The turbine unit has to be put off function. The average annual stoppage time is in order of 536 hours during 27 during the period of operation from 1980 to 2006). After dam heightening the rate of stoppage time has increased to reach 900 hours by year 2015 [8]. This means annual loss of around $18 \mathrm{GWH}$ that costs around 2.7 million US\$.

For the Roseires reservoir by the year 2009, 95\% of the storage volume below the minimum operation level (470 amsl) has been silted up. Fig.(2) shows exposed parts of the sediment delta in fronts of the hydropower intakes. Fig.(3) describes the annual cycle of dredging and sedimentation processes ahead of the intakes. 


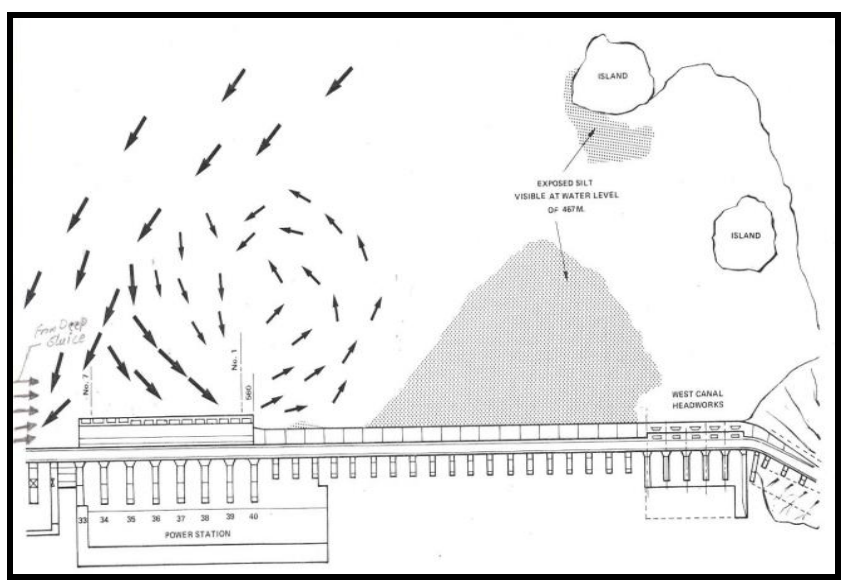

Fig. (2): Observed water flow pattern ahead of Roseires HP intakes (source: [9])

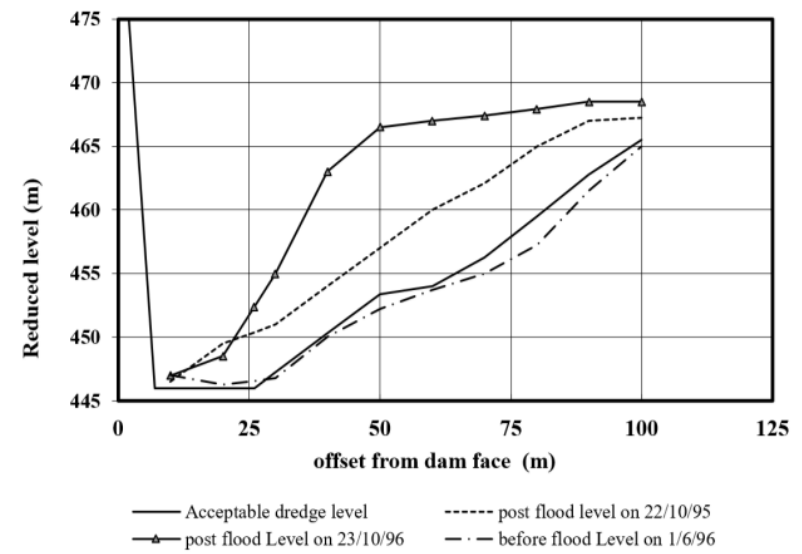

Fig. (3): Profile of the deposited sediment ahead of Roseires Hydropower intakes, season 1995/1996 [10]

Since 1980 to date an average of $121100 \mathrm{~m} 3$ of sediment is annually dredged at an average cost of $5.7 \mathrm{US} \$ / \mathrm{m} 3$ (see Table (I) and Fig. (4)). The volume dredged has risen sharply to 240100 m3/year by year 2015 due to dam heightening on 2010 and raising the minimum operation level by 3 meters, from 467 to $470 \mathrm{~m}$ amsl (See Fig. 5). Saad [8] quantified the financial annual cost due to depreciation of turbine components, loss in performance, blockage of the cooling system, stoppage time energy loss and dredging. The total annual cost was found to be in order of $4.3 \mathrm{M}$ US\$ of which $62 \%$ accounts for the dredging operation alone.
Table I: Delta front levels a head of Roseires

Hydropower intakes (season 1995/1996)

\begin{tabular}{|c|c|c|c|c|c|c|c|}
\hline \begin{tabular}{|c|} 
Offset \\
from \\
dam \\
face (m)
\end{tabular} & $\begin{array}{l}\text { Accep. } \\
\text { dredge } \\
\text { level } \\
\text { (m) }\end{array}$ & $\begin{array}{c}\text { level on } \\
22 / 10 / 95 \\
\text { (m) }\end{array}$ & \begin{tabular}{|c|} 
Level on \\
$23 / 10 / 96$ \\
(m)
\end{tabular} & $\begin{array}{c}\text { Level } \\
\text { on } \\
1 / 6 / 96\end{array}$ & \begin{tabular}{|c|} 
Sed. \\
thicknes \\
(m)
\end{tabular} & $\begin{array}{c}\text { Area } \\
\left(\mathrm{m}^{3}\right)\end{array}$ & $\begin{array}{c}\text { Dep. } \\
\text { Vol. } \\
\left(10^{3}\right. \\
\mathrm{m}^{3} / 10 \\
\mathrm{~m}) \\
\end{array}$ \\
\hline 2 & 475 & & & & 0 & & \\
\hline 7 & 446 & & & & 0 & & \\
\hline 10 & 446 & 447 & 447 & 447 & 0 & 2500 & 0 \\
\hline 20 & 446 & 450 & 449 & 446 & 2 & 2500 & 3 \\
\hline 30 & 447 & 451 & 455 & 447 & 8 & 2500 & 13 \\
\hline 40 & 450 & 454 & 463 & 450 & 13 & 2500 & 27 \\
\hline 50 & 453 & 457 & 467 & 452 & 14 & 2500 & 34 \\
\hline 60 & 454 & 460 & 467 & 454 & 13 & 2500 & 34 \\
\hline 70 & 456 & 462 & 467 & 455 & 12 & 2500 & 32 \\
\hline 80 & 460 & 465 & 468 & 457 & 11 & 2500 & 29 \\
\hline 90 & 463 & 467 & 469 & 462 & 7 & 2500 & 22 \\
\hline 100 & 466 & 467 & 469 & 465 & 4 & 2500 & 13 \\
\hline 200 & & & & & 2 & 25000 & 7 \\
\hline \multicolumn{7}{|c|}{ Total deposited volume to $100 \mathrm{~m}$} & 207 \\
\hline \multicolumn{7}{|c|}{ Projected Volume deposited to $200 \mathrm{~m}$} & 273 \\
\hline
\end{tabular}

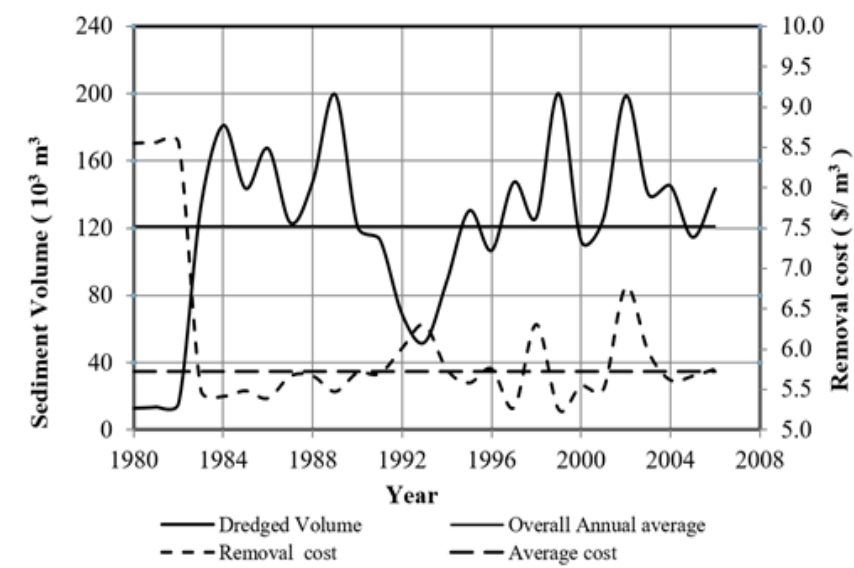

Fig. (4): Historical Data on Dredged sediment volumes and the associated cost (1980-2006)

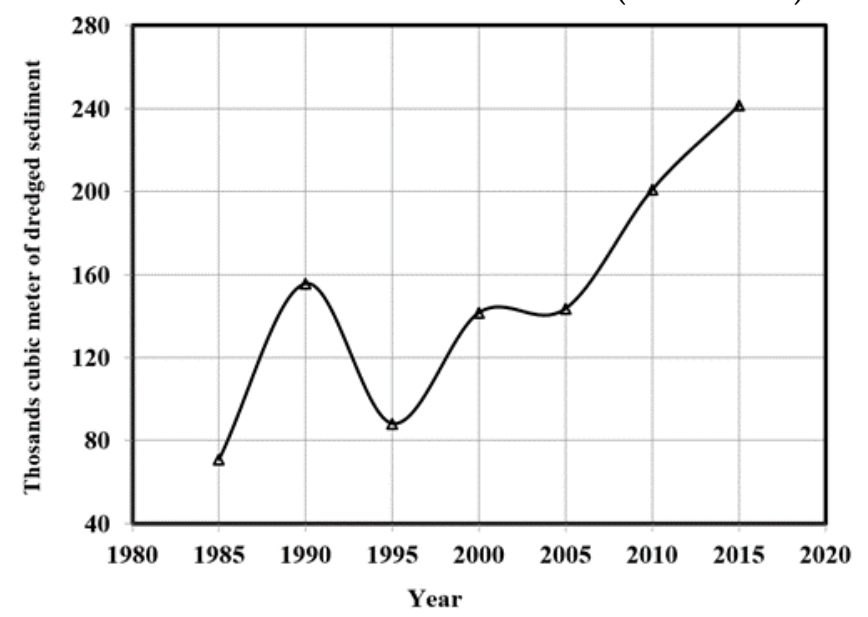

Fig. (5): Five years average of dredged sediment at Roseires HP intakes (1980-2015) (source:[8]) 


\section{B. Literature Review}

\section{Critical Velocity of Sediment Transport in pipes}

From the economical point of view the pipeline system has to be operated optimally. Hence the primary goal is to transport the maximum sediment volume with the minimum energy (head loss) and consequently the minimum required water volume. The sediment in pipes is transported as homogeneous, heterogeneous, and bed load depending on the velocity and sediment particles. The heterogeneous type is most common form in a non-uniform grain size situation and hence it is the most often investigated regime. The bed load or deposit regime is characterized by the presence of deposits, bed load as well as suspended load. Here, the presence of deposits greatly increases the head loss gradient, reduces the flow area and eventually the blockage of the pipe. This subject is of special interest because of its practicability in a multitude of applications, namely in slurry transport, storm sewers, coal and ore transport, sediment capping, dam construction and dredging industry.

Many researchers have investigated the two phase flow of sediment transport in pipes with the interest of determining the non-deposited or non-silting velocity [10], [11], [12], [13], [14], [15], [16], [17], [18] and [19]. Various formulas were derived for computing the critical/non settling velocity $\left(\mathrm{V}_{\mathrm{c}}\right)$ and the optimum concentration $\left(\mathrm{C}_{\mathrm{v}}\right)$. However very few of these relationships are docile for practical design in a similar way to clear water computation. In the following brief description of the general features of the formulae will be outlined.

In 1953 Durand [11] conducted very extensive experiments using a wide range of pipe sizes and sediment concentrations and gave the following general relationship.

$$
J_{m}=J+k\left[\frac{V^{2} \sqrt{C_{d}}}{g d(s-1)}\right]^{m} C_{v} J
$$

Where $\mathrm{J}_{\mathrm{m}}$ and $\mathrm{J}$ are the head loss gradient for flow with and without sediment respectively, $\mathrm{V}=$ velocity of flow, $C_{d}=$ particle drag coefficient, $d=$ pipe diameter, $\mathrm{C}_{\mathrm{v}}=$ sediment concentration by volume, $\mathrm{s}=$ sediment specific gravity $\left(\mathrm{Q}_{\mathrm{s}} / \mathrm{Q}\right)$, and $\mathrm{g}$ = acceleration due to gravity, $Q_{s}=$ density of sediment and $\varrho=$ water density. The values for the coefficients $\mathrm{m}$ and $\mathrm{k}$ have been given by Durand [11] as -1.5 and 81 respectively. The clear water head loss gradient $\mathrm{J}$ is given by the well-known Darcy-Weisbach formula (Eq. (2)).

$$
J=f \frac{V^{2}}{2 g d}
$$

Both [17] and [20] studied Durand's general formula and tried to compute the limiting velocity for optimum sediment transport by differentiating $C_{v}$ in Eq. (1) with respect to $V$ and equating it to zero. They both arrived to Eq. (3) for the limiting velocity.

$$
V_{m}=3.43\left[\frac{g d(s-1)}{\sqrt{C_{d}}}\right]^{\frac{1}{2}} C_{v}^{\frac{1}{3}}
$$

It has been argued that the above equation is occasionally not reliable as it underestimates the limiting velocity reported in experimental observations [17].

Herbich [21] conducted dimensional analysis and proposed a modified form of Darcy-Weisbach for calculating the friction loss in pipes (Eq. (4))

$$
J_{m}=s_{m} \frac{f}{d} \cdot \frac{V^{2}}{2 g}
$$

Where $\mathrm{sm}_{\mathrm{m}}=$ specific gravity of the slurry mixture, $\mathrm{f}$ $=$ Darcy-Weisbach friction factor (estimated from the Moody Diagram). When the fluid is water, the specific gravity of the slurry mixture $\mathrm{sm}$, and the slurry concentration by volume $C_{v}$ were obtained using Eq. (5) and Eq. (6)

$$
\begin{gathered}
C_{w}=\frac{s}{s_{m}} \frac{\left(s_{m}-1\right)}{(s-1)} \\
C_{v}=\frac{s_{m}}{s}
\end{gathered}
$$

Where $s$ is the sediment specific gravity and $C_{w}$ is the concentration by weight (for water $1 \mathrm{mg} / \mathrm{l}=$ 1 ppm).

Experimental data of [15], [16] and [23] were utilized by [22] to produce a relationship (Eq. (7)) that relates the sediment concentration to the limiting velocity $\mathrm{V}_{\mathrm{m}}$, Hydraulic radius $\mathrm{R}$, sediment relative density $\mathrm{s}$, and sediment grain size D.

$$
C_{v}=\frac{1}{1276}\left[\frac{V_{m}}{\sqrt{g D(s-1)}}\right]^{4.762}\left(\frac{D}{R}\right)^{2.571}
$$


Modified Darcy-Weisbach Equation for optimum Sediment Transport in Pipes

Siyam [24] followed similar procedure as that carried by [17] and [20] in using Durand's general formula Eq. (1). However, [24] nullified the derivative of the sediment discharge $\mathrm{Q}_{\mathrm{s}}$, and not the concentration $\mathrm{C}_{\mathrm{v}}$, with respect to the velocity $\mathrm{V}$. The given logic was that $\mathrm{C}_{\mathrm{v}}$ is a dependent variable on $Q_{s}$ and $V\left(C_{v}=Q_{s} / A V\right)$. This corrected for the underestimation pointed out to by [17] and [20]. Siyam [24] obtained two separate equations, Eq. (8) and Eq. (9). They are respectively for determining the critical velocity $\mathrm{V}_{\mathrm{c}}$ and the optimum sediment concentration $\mathrm{C}_{\mathrm{vc}}$. The full derivation can be found in [24] but brief outline is given here as follows:

$$
\begin{gathered}
I_{m}=\left(\frac{2 m-1}{2 m+1}\right) f \frac{V_{c}^{2}}{2 g d} \\
C_{v c}=\frac{-2}{k(2 m+1)}\left[\frac{V_{c}^{2} \sqrt{C_{d}}}{g d(s-1)}\right]^{-m}
\end{gathered}
$$

Equation (8) is a very important finding because it relates the water sediment mixture head loss gradient Jm to the clear head loss gradient by a constant of proportionality which depends only on Durand's power m.

For this study Eq. (8) and Eq. (9) with Durand's parameters $m=-1.5$ and $k=81$ were selected to be used as they are simple to be used in conjunction with the conventional procedure for designing pipeline carrying clear water. The formula given by [21] i.e. Eq. (4) is of similar form but it underestimates the friction induced by sediment mixture. Hence, Eq. (8) and Eq. (9) may be respectively simplified to Eq. (10) and Eq. (11).

$$
\begin{gathered}
J_{m}=2 f \frac{V_{c}^{2}}{2 g d} \\
C_{v c}=\frac{1}{81}\left[\frac{V_{c}^{2} \sqrt{C_{d}}}{g d(s-1)}\right]^{1.5}
\end{gathered}
$$

Further proof that $\mathrm{V}_{\mathrm{c}}$ and $\mathrm{C}_{\mathrm{vc}}$ given by Eq. (10) and Eq. (11) are the required critical velocity and the optimum sediment transport can be found in [24] where a sediment transport index as a measure of transport efficiency is introduced and shown diagrammatically. The focus from here onward will concentrate on detailing the procedure for performing the computation of optimum sediment mixture in a pipe flow in manner similar to a carrying pipe clear water.

\section{Minor Losses}

For the minor losses through the pipeline system it will be quantified as fraction of velocity head. Hence if the gross available water head is given by $\mathrm{H}$, then the net energy slope that is available for transporting the sediment, through a pipe of length L, will be according to Eq. (12)

$$
J_{m}=\left(H-\frac{k_{l} V^{2}}{2 g}\right) \frac{1}{L}
$$

Where, $\mathrm{kl}$ is the total minor loss coefficient through the pipeline system and equals to the sum of individual minor loss coefficients.

\section{Friction Equation}

In addition to the equations derived earlier an equation for evaluating the friction factor (f) is required for closure. For this purpose, either Colebrook-White implicit transition formula or Barr explicit formula can be used. They are respectively given by Eq. (13) and Eq. (14).

$$
\begin{gathered}
\frac{1}{\sqrt{f}}=-2 \log \left(\frac{k_{s}}{3.7 d}+\frac{2.51}{R_{e} \sqrt{f}}\right) \\
\frac{1}{\sqrt{f}}=-2 \log \left(\frac{k_{s}}{3.7 d}+\frac{5.12862 .51}{R_{e}^{0.89}}\right)
\end{gathered}
$$

Where $\mathrm{k}_{\mathrm{s}}$ is the pipe roughness, $\mathrm{R}_{\mathrm{e}}$ is the Reynolds number of pipe flow $\left(R_{e}=V d / v\right)$, and $v$ is the kinematic viscosity of the fluid.

\section{Design Guideline for Pipeline Transporting Sediment at Optimum Capacity.}

The procedure will be outlined in the following steps. A Schematic flow chart is given in Fig. (6).

(1) Reservoir characteristics: Determine the available head $(\mathrm{H})$, and the length of pipe (L) which is equal to the distance between the sediment intake and the discharging point on the downstream of the dam.

(2) Select a trial pipe size (d) and determine its effective roughness height $\mathrm{k}_{\mathrm{s}}$

(3) Assume a pipeline velocity $\mathrm{V}$, and calculate the effective or net head loss gradient $\mathrm{J}_{\mathrm{m}}$, taking the total minor head losses into account using Eq. (12). 
(4) Evaluate flow Reynolds $\left(\mathrm{Re}_{\mathrm{e}}=\mathrm{Vd} / \mathrm{v}\right)$ number and compute the friction coefficient (f) using either Eq. (13) or Eq. (14).

(5) Use the modified Darcy-Weisbach formula Eq. (10) to calculate the critical velocity $V_{c}$.

(6) Compare the calculated $V_{c}$ with the assumed velocity $V$. If different use $V_{c}$ as new $\mathrm{V}$ and repeat steps 3,4 , and 5 until values of $\mathrm{V}$ and $\mathrm{V}_{\mathrm{c}}$ are reasonably matching. Only few trials are necessary.

(7) Compute the particle Reynolds number ( $R_{e p}$ $\left.=\mathrm{W}_{\mathrm{s}} \mathrm{D}_{50} / \mathrm{v}\right)$ and then compute the particle Drag coefficient $\mathrm{Cd}$ using Table (II). The parameter $\mathrm{W}_{\mathrm{s}}$ is the settling velocity of the mean particle size $\mathrm{D}_{50}$. However, ws depend on the range of Rep. Hence an iteration process is necessary.

Table II: Expressions for Drag Coefficient at Different Rep

\begin{tabular}{|c|c|c|c|}
\hline & Settling Velocity & Drag Coefficient & Condition \\
\hline 1 & $(\mathrm{~m} / \mathrm{s})$ & $(-)$ & \\
\hline 2 & $V_{0}=\left[\frac{g\left(\rho_{S}-\rho_{L}\right) d^{2}}{18 \mu_{L}}\right]$ & $C_{D}=\left(\frac{24}{R e}\right)$ & $\operatorname{Re}<1$ \\
\hline 3 & $V_{0}=\frac{0.2 d^{1.18}\left[\frac{g\left(\rho_{S}-\rho_{L}\right.}{\rho_{L}}\right]^{0.72}}{\left(\frac{\mu_{L}}{\rho_{L}}\right)^{0.45}}$ & $C_{D}=30 R e^{-0.625}$ & $1<\operatorname{Re}<1000$ \\
\hline 4 & $V_{0}=\left[4 g d\left\{\frac{\rho_{S}-\rho_{L}}{3 \times 0.44 \rho_{L}}\right\}^{0.5}\right.$ & $C_{D}=0.44$ & $1000<\operatorname{Re}<2 \times 10^{5}$ \\
\hline & $V_{0}=\left[4 g d\left\{\frac{\rho_{S}-\rho_{L}}{3 \times 0.1 \rho_{L}}\right\}\right]^{0.5}$ & $C_{D}=0.1$ & $\operatorname{Re}>2 \times 10^{5}$ \\
\hline
\end{tabular}

Initially one should assume Rep range, calculates $\mathrm{W}_{\mathrm{s}}$ with the appropriate equation in Table (II), and then calculates Rep using the calculated Ws. If the Rep is in the assumed range, the calculated $\mathrm{W}_{\mathrm{s}}$ is correct. If the Reynolds number is not in the correct range for the equation used, use a different equation to recalculate the settling velocity $\mathrm{w}_{\mathrm{s}}$. Repeat these steps as necessary. In case the sediment is a mixture of different sizes, then the composite drag coefficient $C_{\mathrm{dm}}$ for the sediment material must be used. The composite drag coefficient may be evaluated from Eq. (15) as given by [25].

$$
\sqrt{C_{d m}}=P_{1} \sqrt{C_{d 1}}+P_{2} \sqrt{C_{d 2}}+\cdots+P_{n} \sqrt{C_{d n}}
$$

Where $P_{1}, P_{2}$, and $P_{n}$ are decimal size fractions of the grain size distribution and $\mathrm{C}_{\mathrm{d} 1}, \mathrm{C}_{\mathrm{d} 2}$, and $\mathrm{C}_{\mathrm{dn}}$ are the drag coefficients of the particle diameters used to represent the sediment size fraction.

(8) Calculate the optimum sediment transport capacity $\left(\mathrm{C}_{\mathrm{vc}}\right)$ using Eq. (11) with the last value of $V_{c}$ and the computed drag coefficient $C_{d}$.

\section{RESULTS OF APPLICATION TO ROSEIRES HYDROPOWER INTAKES}

From the historical experience of sediment dredging in front of the HP intakes of Roseires reservoir the proposed system has to dredge annually a volume of $207 \times 10^{3} \mathrm{~m}^{3}$ of silt within 100 $\mathrm{m}$ from the intakes (area of $25000 \mathrm{~m}^{2}$ ). An extra volume of $66 \times 10^{3} \mathrm{~m}^{3}$ is projected for the range between $100 \mathrm{~m}$ and $200 \mathrm{~m}$ from the dam face (area of $25000 \mathrm{~m}^{2}$ ).

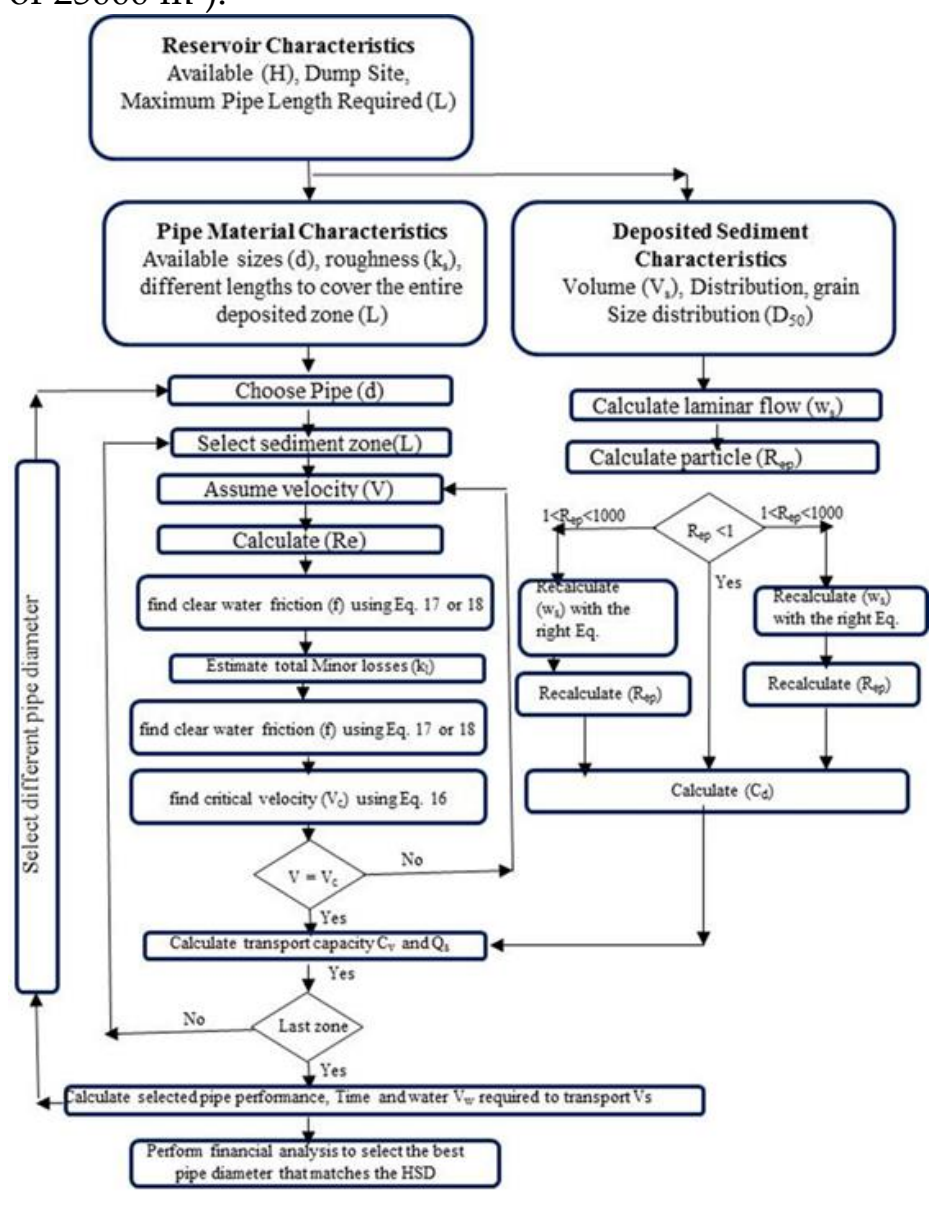

Fig. (6): Flow chart for selecting the optimal pipe size for removal of deposited sediment.

The sediment distribution is assumed to be deposited in accordance with the year 1996 surveyed profile and laid uniformly across all intakes in a width range of $300 \mathrm{~m}$. Fig. (7) shows the distribution pattern of the deposited sediment 
in terms of distance from the intakes. The pipeline length to the downstream discharging location is taken as $100 \mathrm{~m}$ from the upstream face of the dam and passes through the dam body. It is suggested that the pipeline could be passed through the penstock of the service power station which is $3 \mathrm{~m}$ in diameter and currently out of service. In the forgoing computation the pipeline system will be assumed to be operated concurrently with the HDR system. The optimum required sediment concentration, that will be determined here, is automatically fed.

The above calculation procedure was implemented to calculate the optimum sediment transport capacity of the main pipe taking the average grain size of sediment as $0.17 \mathrm{~mm}$ as measured by [8]. The gross available head is taken as $20 \mathrm{~m}$. This corresponds to the difference in level between $455 \mathrm{~m}$ amsl, the discharging level on the downstream, and the average reservoir level of $475 \mathrm{~m}$. The historical recorded maximum downstream water level is level of $450 \mathrm{~m}$ amsl. Table (III) gives the detailed calculation when a pipeline with diameter $\mathrm{d}=1.0 \mathrm{~m}$ is considered. The table also shoes the transport capacity at different sediment zones and the furthest distance within each zone.

Table III: Calculation Sequence for Determining sediment \& water volumes and Time of removal $(\mathrm{D}=1.0 \mathrm{~m})$

\begin{tabular}{|c|c|c|c|c|c|c|}
\hline \multicolumn{7}{|c|}{ Water flow computation } \\
\hline$(1)$ & $(2)$ & $(3)$ & $(4)$ & $(5)$ & $(6)$ & $(7)$ \\
\hline $\begin{array}{c}\text { Pipe } \\
\text { length } \\
(\mathbf{m})\end{array}$ & $\begin{array}{c}\text { Energy } \\
\text { slope } \\
(\mathbf{m} / \mathbf{m})\end{array}$ & $\begin{array}{c}\text { Assumed } \\
\text { Velocity } \\
(\mathbf{m} / \mathbf{s})\end{array}$ & $\begin{array}{c}\text { Net } \\
\text { Energy } \\
\text { slope } \\
\mathbf{J m}\end{array}$ & $\begin{array}{c}\text { Flow } \\
\text { Reynolds } \\
\text { Re }\end{array}$ & $\begin{array}{c}\text { Friction } \\
\mathbf{( f )}\end{array}$ & $\begin{array}{c}\text { Critical } \\
\text { velocity } \\
(\mathbf{m} / \mathbf{s}) \\
\mathbf{V} \mathbf{c}\end{array}$ \\
\hline 125 & 0.160 & 5.73 & 0.0662 & 5734000 & 0.020 & 5.74 \\
150 & 0.133 & 5.51 & 0.0610 & 5514000 & 0.020 & 5.51 \\
175 & 0.114 & 5.31 & 0.0568 & 5310000 & 0.020 & 5.31 \\
200 & 0.100 & 5.13 & 0.0530 & 5134000 & 0.020 & 5.13 \\
225 & 0.089 & 4.97 & 0.0497 & 4970000 & 0.020 & 4.97 \\
275 & 0.073 & 4.69 & 0.0442 & 4690000 & 0.020 & 4.69 \\
300 & 0.067 & 4.56 & 0.0419 & 4560000 & 0.020 & 4.56 \\
325 & 0.062 & 4.45 & 0.0398 & 4450000 & 0.020 & 4.45 \\
350 & 0.057 & 4.34 & 0.0379 & 4340000 & 0.020 & 4.34 \\
375 & 0.053 & 4.24 & 0.0362 & 4240000 & 0.020 & 4.24 \\
425 & 0.047 & 4.06 & 0.0332 & 4060000 & 0.020 & 4.06 \\
450 & 0.044 & 3.98 & 0.0319 & 3980000 & 0.020 & 3.98 \\
475 & 0.042 & 3.90 & 0.0307 & 3900000 & 0.020 & 3.90 \\
500 & 0.040 & 3.83 & 0.0295 & 3830000 & 0.020 & 3.83 \\
600 & 0.033 & 3.57 & 0.0257 & 3574000 & 0.020 & 3.57 \\
\hline
\end{tabular}

Table III: Continued.

\begin{tabular}{|c|c|c|c|c|c|c|c|c|}
\hline \multicolumn{5}{|c|}{ Optimum sediment concentration (Cv) } & \multicolumn{4}{|c|}{$\begin{array}{c}\text { Pipe system Performance } \\
\text { (Sediment \&water volumes and } \\
\text { time Required) }\end{array}$} \\
\hline (8) & (9) & (10) & (11) & (12) & (13) & (14) & (15) & (16) \\
\hline $\begin{array}{l}\text { Optimum } \\
\text { sediment } \\
\text { conc. } \\
\text { (Cv) }\end{array}$ & $\begin{array}{c}\text { Removal } \\
\text { Cap. } \\
\left(10^{3} \mathrm{~m}^{3}\right. \\
/ \text { day })\end{array}$ & $\begin{array}{c}\text { Max. } \\
\text { distance } \\
\text { in zone } \\
(\mathrm{m})\end{array}$ & $\begin{array}{c}\text { Average } \\
\text { critical } \\
\text { Velocity } \\
\text { in } \\
\text { lateral }\end{array}$ & $\begin{array}{c}\text { Average } \\
\text { Optimum } \\
\text { Conc. in } \\
\text { zone }\end{array}$ & $\begin{array}{c}\text { Average } \\
\text { Removal } \\
\text { Cap. } \\
\text { (10 m } \\
\text { /day) }\end{array}$ & $\begin{array}{c}\text { Accum. } \\
\text { Sed. } \\
\text { Vol.( } \\
\left.10^{2} \mathrm{~m}^{3}\right)\end{array}$ & $\begin{array}{c}\text { Removal } \\
\text { Time } \\
\text { Required } \\
\text { (days) }\end{array}$ & $\begin{array}{c}\text { Qty. } \\
\text { of } \\
\text { water } \\
\text { used } \\
\left(10^{6}\right. \\
\left.\mathrm{m}^{5}\right)\end{array}$ \\
\hline 0.2265 & 29.37 & 275.00 & 5.21 & 0.1750 & 22.69 & 16 & 0.70 & 0.08 \\
\hline 0.2005 & 24.97 & 300.00 & 5.04 & 0.1573 & 19.59 & 61 & 3.09 & 0.35 \\
\hline 0.1801 & 21.64 & 325.00 & 4.88 & 0.1428 & 17.16 & 81 & 4.72 & 0.52 \\
\hline 0.1622 & 18.82 & 350.00 & 4.74 & 0.1302 & 15.10 & 50 & 3.29 & 0.35 \\
\hline 0.1474 & 16.57 & 375.00 & 4.61 & 0.1195 & 13.43 & & & \\
\hline 0.1235 & 13.08 & 425.00 & 4.37 & 0.1019 & 10.80 & & & \\
\hline 0.1141 & 11.78 & 450.00 & 4.27 & 0.0949 & 9.79 & 66 & 5.65 & 0.55 \\
\hline 0.1055 & 10.61 & 475.00 & 4.17 & 0.0884 & 8.89 & & & \\
\hline 0.0982 & 9.64 & 500.00 & 4.09 & 0.0828 & 8.12 & & & \\
\hline 0.0916 & 8.78 & 525.00 & 3.91 & 0.0732 & & & & \\
\hline 0.0804 & 7.38 & 575.00 & 2.03 & 0.0402 & to $100 \mathrm{~m}$ & 207 & 12 & 1.3 \\
\hline 0.0756 & 6.80 & 600.00 & 1.99 & 0.0378 & & & & \\
\hline 0.0713 & 6.29 & 625.00 & 1.95 & 0.0357 & & & & \\
\hline 0.0674 & 5.83 & 650.00 & 1.91 & 0.0337 & & 273 & 17 & 1.9 \\
\hline 0.0548 & 4.42 & 750.00 & 179 & 0.0274 & & & & \\
\hline
\end{tabular}

The time required and water volume used by the system to remove all the deposited sediment in accordance to the distribution depicted in Fig. (7) was also computed. Fig. (8) gives the performance curves for different pipes sizes. The time and water volume required by different pipes is illustrated in Fig. (9).

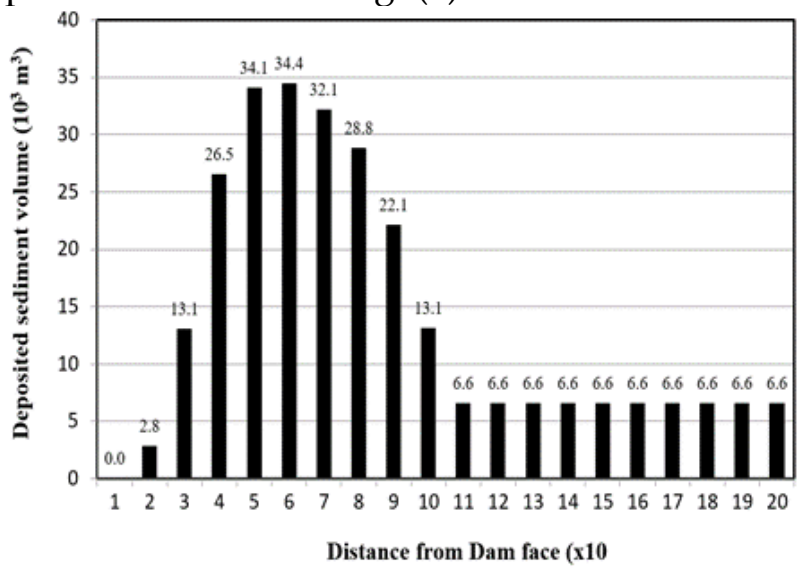

Fig. (7): Distribution of the deposited sediment in front of Roseires Hydropower Intakes (1996)

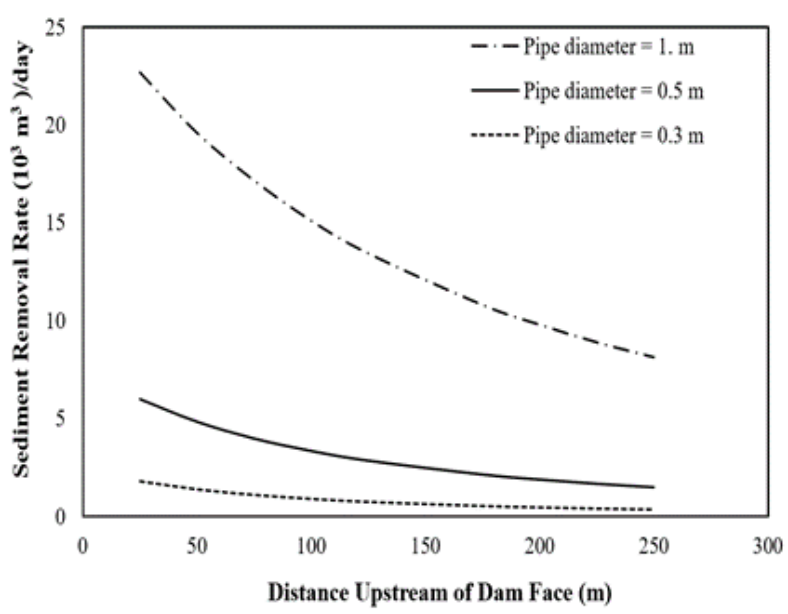

Fig. (8): Performance curves of the Pipeline System with different pipe sizes 


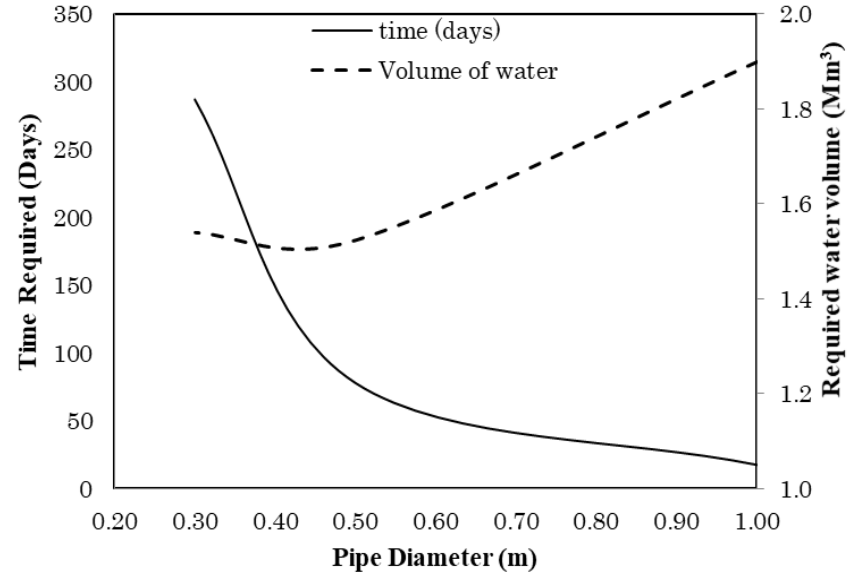

Fig. (9): General system requirements for removal of the specified deposited sediment

\section{DISCUSSION}

(1) Generally, the performance curves showed the expected characteristics of diminishing transportation capabilities as the pipe length increases. For example, the $1.0 \mathrm{~m}$ diameter pipes, its capacity reduced from $22.7 \times 10^{3} \mathrm{~m}^{3} /$ day to $8.1 \times 10^{3} \mathrm{~m}^{3} /$ day for the distance range from 25 $\mathrm{m}$ to $250 \mathrm{~m}$ from the dam face (i.e. pipe length $275 \mathrm{~m}$ to $500 \mathrm{~m}$ ). The corresponding values for the $0.5 \mathrm{~m}$ diameter pipe are $6 \times 10^{3} \mathrm{~m} 3 /$ day and $1.5 \times 10^{3} \mathrm{~m}^{3} /$ day respectively, and for the $0.3 \mathrm{~m}$ diameter pipe are $1.8 \times 10^{3} \mathrm{~m}^{3} /$ day and $0.37 \times 10^{3}$ $\mathrm{m}^{3} /$ day respectively.

(2) When the transportation capacities of the three pipes is weighted against the expected volumes of the deposited sediment with the given distribution in Fig. (7), the total time and water volumes required for removal were obtained. It was found that, the time required for the $1.0 \mathrm{~m}, 0.5 \mathrm{~m}$, and $0.3 \mathrm{~m}$ diameter pipes to remove the deposited sediment were 12, 50 and 180 days respectively for the sediment in range of $100 \mathrm{~m}$ from the dam face. The corresponding times for removing sediment in the range up to $200 \mathrm{~m}$ were 17, 78 and 287 days respectively. The volumes of water used by the three systems were respectively found to be 1.9, 1.52 and 1.54 Million $\mathrm{m}^{3}$.

(3) In accordance to the reservoir operation dredging is usually conducted after the end of the flood season which takes place during June to October i.e. there is an approximate of seven months (210 days) to perform the dredging. In this respect the first two pipes, with diameters
$1.0 \mathrm{~m}$ and $0.5 \mathrm{~m}$ satisfies this criterion but for the third pipe with diameter $0.3 \mathrm{~m}$ requires longer time to remove sediment in $100 \mathrm{~m}$ to $200 \mathrm{~m}$ reach. Again a part from the cost concern, the $1.0 \mathrm{~m}$ pipe and due to its high performance, require relatively a very short time (17 days) to remove the deposited sediment. Such time require very efficient HSD and ease of maneuvering the system to cover the entire area of $50000 \mathrm{~m}^{2}$ at the bottom of reservoir. System cost and maintenance has to be considered.

(4) From the forgoing mentioned point the parameters for optimizing the system can be reasoned. The pipe line cost and the cost of the corresponding HSD required has to be taken as an integrated system to constitute the construction cost. The time required and ease of maneuvering the system has to be taken to represent the maintenance cost. The best system can then be decided based on the least cost approach.

(5) Considering the current annual average cost of $0.7 \mathrm{M}$ US $\$$ for dredging only $121 \times 10^{3} \mathrm{~m}^{3}$ of sediment, during 27 years of operation (1980-2006), the feasibility of the new system can be assessed. In fact [8] added an extra 0.2 M US\$ as a direct cost of energy loss due to forced stoppage time of the turbine units. He computed the average annual stoppage time as 536 hours during the 27 years of operation and increased to 900 hours by year 2015 .

\section{CONCLUSIONS}

Sedimentation is an inevitable process that faces all dam world-wide. Sustainability of reservoir's function will be achieved only when sediment releases is managed. It is important to design suitable combination of water flow and sediment release that can meet the demands of reservoir functions, downstream river morphology and ecosystem. Integrated sediment management should consider in a sediment routing system which covers the basin scale. Valuable conclusions can be drawn from this study.

(1) The study managed to draw guidelines for selecting a pipe size for optimum sediment transport in a similar fashion to the 
conventional clear water flow computation.

(2) The utilization of natural available water head in preserving the storage or clearing the intakes seems very attractive and it is a sustainable resource that needs to be utilized to prolong the life service of hydropower. Thus the importance of managing the sediment may even necessitates converting one of the hydropower penstocks to route the sucked sediment if other options of syphoning is limited.

(3) The current annual incurred cost of sediment removal in Roseires reservoir is kept in increasing order especially after dam heightening. Adoption and implementation of a new sustainable sediment management facility seems to be attractive and inevitable.

(4) The proposed system needs a well-regulated sediment feeding system (Hydro-suction) and if combined with the recent development of ejector pump in Japan as a sediment feeding system may be part of the integral solution.

\section{REFERENCES}

[1] K. Mohmood, Reservoir Sedimentation: Impact, Extent, and Mitigation. World Bank Technical Report Number 71, 1987, The World bank, Washington, D.C

[2] G. L. Morris, and J. Fan, Reservoir sedimentation hand-book, New York, McGraw-Hill, 1998.

[3] S. A. Kantoush, T. Sumi, and Y. Takemon, "Lighten the load," International water power and dam construction, PP 38-45, 2011.

[4] G. M. Kondolf, Y. Gao, G. W. Annandale,G. L. Morris, E. Jiang, J. Zhang, P. Carling, K. Fu, Q. Guo, R. Hotchkiss, C. Peteuil, T. Sumi, H. W. Wang, Z. Wang, Z. Wei, B. Wu, and C. T. Yang, (2014). "Sustainable sediment management in reservoirs and regulated rivers: Experiences from five continents". Earth's Future 2(5), pp. 256-280, 2014.

[5] G. R. Basson, and A. Rooseboom, Dealing with Reservoir Sedimentation- Dredging, Water Research Commission Report No. TT 110/99, ISBN 186845 4932, South Africa, 1999.

[6] M. Meshkati Shahmirzadi, T. Sumi, S. A. Kantoush,T. Temmyo, "Influence of Air Injection on Suction Power and Pressure Gradient in Dredger System" Journal of Hydraulic Engineering, Japan Society of Civil Engineering, Vol.68, No.4, 37- 42, 2012.

[7] T. Sumi, S. A. Kantoush, H. Itoh, T. Sase, and T. Satoh, "Experimental Study on Siphon Dredging System at Wonogiri Multipurpose Dam," Proceeding of Hydropower and Dams, AFRICA, Marrakech, Morocco, 2017.

[8] E. A. Saad, "Impact of Sediment and Sedimentation on Hydropower Generation: Case of Roseires Reservoir" Ph.D. Thesis, UNESCO Chair in Water Resources, Omdurman Islamic University, Sudan, 2017

[9] P. Nilson, and J. Blanton, Impact Evaluation Report-Sudan: Roseires Irrigation Project, World Bank Technical Report
Number 3051, 1980, The World bank, Washington, D.C.

[10] A. M. Siyam, "Reservoir Sedimentation Control" Ph.D. Thesis, University of Bristol, England, 2000.

[11] R. Durand, "Basic Relationships of the Transportation of Solids in Pipes: Experimental Research," Proceedings of the 5th. Congress, IAHR, Minneapolis, 1953.

[12] R. J. Garde, Sediment transport through pipes. Department of Civil Engineering, Colorado Agricultural and Mechanical College, Fort Collins, Colorado, CER No. 0590837, 1956.

[13] V. A. Vanoni, Sedimentation Engineering. ASCE Manual No. 54, ASCE, New York, N.Y., 1975.

[14] E. Condolios, and E. E. Chapus, "Transporting Solid Material in the Pipelines," Chem. Engineering, 70(6), PP 93-98, Mcgraw-Hill, 1963.

[15] R. Mayerle, C. Nalluri, and P. Novak, "Sediment Transport in Rigid Bed Conveyances," Journal of Hydraulic Research, Vol. 29, No. 4, April, 1991.

[16] A. A. Ghani, "Sediment Transport in Sewers," PhD Thesis, University of Newcastle upon Tyne, UK, 1993.

[17] S. Eftekharzadeh, "Sediment Bypass system for Impounding Reservoirs," PhD Dissertation, Dept. of Civil Eng. and Eng. Mech., University of Arizona, Tucson, Ariz, 1987.

[18] R. H. Hotchkiss, and Xi Haung, "Hydro-suction Sediment-Removal Systems (HSRS): Principles and Field Test," ASCE Journal, Vol. 121, No. 6, June, 1995.

[19] R. H. Hotchkiss, and F. H. Bollman, "Socio-economic Analysis of Reservoir Sedimentation," The 27th Congress of the International Association for Hydraulic Research, Energy and power: Sustainable development, San Francisco, California, PP 79-83, Aug. 10-15, 1997.

[20] E. T. Goedde, "To the Critical Velocity of Heterogeneous Hydraulic Transport," Hydro Transport 5, Vol.2, Hannover, Germany, 1978.

[21] Handbook of Dredging Engineering, Second Edition, McGraw-Hill. J. B. Herbich, New York, 2000.

[22] E. Isa, B. Hossein and S. Ali, "Design criteria for sediment transport in sewers based on self-cleansing concept," Journal of Zhejiang University SCIENCE A, Volume 15, Issue 11, PP 914-924, November 2014.

[23] N. Vongvisessomjai, T. Tingsanchali, and M. S. Babel, "Non-deposition design criteria for sewers with partfull flow," Urban Water Journal, 7(1), PP 61-77. 2010

[24] A.M. Siyam, "Optimum Sediment Transport in Pipes with Non-Deposited beds" Nile Water Science\& Engineering Journal, Volume 9, Issue 1, PP 1-11, December 2016.

[25] W. H. Graf, "Hydraulics of Sediment Transport," New York: McGraw-Hill, Inc, 1971. 